\title{
A Framework For Step Down Or Therapeutic Re-Organization For Withdrawal Of Inhaled Corticosteroids In Selected Patients With COPD: A Proposal For COPD Management
}

This article was published in the following Dove Press journal:

International Journal of Chronic Obstructive Pulmonary Disease

\author{
Claudio Micheletto' \\ Fulvio Braido ${ }^{2}$ \\ Marco Contoli (iD ${ }^{3}$ \\ Fabiano Di Marco (iD) \\ Pierachille Santus ${ }^{5}$ \\ 'Respiratory Unit, Azienda Ospedaliera \\ Universitaria Integrata, Verona, Italy; \\ ${ }^{2}$ Department of Internal Medicine, \\ Respiratory Diseases and Allergy Clinic, \\ University of Genova, Azienda Policlinico \\ IRCCS San Martino, Genoa, Italy; \\ ${ }^{3}$ Department of Medical Sciences, \\ University of Ferrara, Ferrara, Italy; \\ ${ }^{4}$ Department of Health Sciences, \\ Università degli Studi di Milano, \\ Respiratory Unit, Papa Giovanni XXIII \\ Hospital, Bergamo, Italy; ${ }^{5}$ Department of \\ Health Sciences, Università degli Studi di \\ Milano,Pulmonary Unit, Luigi Sacco \\ University Hospital, ASST \\ Fatebenefratelli, Milan, Italy
}

Correspondence: Claudio Micheletto Respiratory Unit, Azienda Ospedaliera Universitaria Integrata, Piazzale Stefani I, Verona $37 \mid 22$, Italy

Tel +390458122248

Email claudio.micheletto@univr.it

\begin{abstract}
While chronic obstructive pulmonary disease (COPD) continues to be a major cause of morbidity and mortality, pharmacological therapy has a definite benefit on symptoms as well as the frequency and severity of exacerbations, and general health. The most recent Global Initiative for Obstructive Lung Disease (GOLD) guidelines recommend triple therapy (long-acting beta 2 agonists [LABA] + long-acting muscarinic antagonists [LAMA] + inhaled corticosteroids [ICS]) only for patients with exacerbations, elevated eosinophils, and without control using a LABA/LAMA or ICS/LABA combination. Long-term monotherapy with ICS is not currently recommended, but may be considered in association with LABAs in patients with a history of exacerbations and elevated eosinophils in spite of appropriate treatment with long-acting bronchodilators. However, long-term use of ICS in combination therapy has been associated with adverse effects, even if widely used in routine management for decades. The available evidence suggests that ICS can be rationally discontinued in patients with stable disease and is not likely to have unfavorable effects on lung function, overall health, or be associated with a greater risk of exacerbations. Indeed, it is widely accepted that ICS therapy should be limited to a small proportion of patients after careful assessment of the individual risk-benefit profile. Unfortunately, however, there are no international recommendations that provide specific guidance or a protocol for withdrawal of ICS. Herein, the available evidence on the use of ICS is reviewed and an easy to use tool is proposed that can provide clinicians with a simple management scheme to guide the most appropriate therapy for management of COPD and use of ICS. In management of COPD, a highly personalized approach is advocated so that the most appropriate therapy for each individual patient can be selected.
\end{abstract}

Keywords: COPD, exacerbation, inhaled corticosteroids, LABA, LAMA, deprescribing

\section{Introduction}

Despite advances in therapy, chronic obstructive pulmonary disease (COPD) remains a major cause of both morbidity and mortality. ${ }^{1,2}$ Pharmacological therapy for COPD has a definite positive impact on the disease as it can improve symptoms and the frequency and severity of exacerbations, and ameliorate both exercise tolerance and general health. ${ }^{3}$ At present, the principal options for management of COPD include a relatively small number of drug classes, namely bronchodilators (short- and long-acting beta2 agonists [SABAs, and LABAs], short- and 
long-acting muscarinic antagonists [SAMAs, and LAMAs]), along with inhaled corticosteroids (ICSs) and PDE-4 inhibitors.

The main goals of therapy for COPD are prevention and control of symptoms, diminish both frequency and severity of exacerbations, and to improve exercise tolerance and the overall quality of life. Monotherapy with a long-acting bronchodilator has the potential to increase lung function and symptoms, as well as enhance exercise performance and reduce the number of exacerbations. ${ }^{4,5}$ Concomitant administration of LABA/LAMA significantly improves lung function vs a single bronchodilator. ${ }^{6}$

The most recent update of the Global Initiative for Obstructive Lung Disease (GOLD) recommends triple therapy (ICS + LABA + LAMA) only for patients with exacerbations and elevated eosinophil levels who are not controlled with a LABA/LAMA or ICS/LABA combination. ${ }^{3}$ Given that the agents used in triple therapy all have dissimilar mechanisms of action, this provides the basis for their concomitant use to optimize the prevention of exacerbation and potential clinical benefits according to pivotal studies. $^{7,8}$ Today, triple therapy is used extensively, and according to a recent review on general practice in the UK over a 5-year period (2004 to 2009), the use of triple therapy more than doubled in patients with very severe COPD. ${ }^{9}$ Moreover, a real-world study in Italy showed that $6.3 \%$ of patients with newly diagnosed disease were prescribed triple inhaled therapy with ICSs, and that $42 \%$ of these patients initiated triple therapy at diagnosis; in that study, older male gender and use of ICS/LABA FDC at diagnosis appeared to correlate most with prescription of triple therapy. ${ }^{10}$ In support of such a strategy, a recent systematic review and meta-analysis concluded that, compared to monotherapy or dual therapy, triple therapy is associated with fewer moderate or severe exacerbations of COPD and improved lung function. ${ }^{11}$

In the current GOLD recommendations, it is acknowledged that there is a lack of high-quality evidence that supports the initial strategies for pharmacological treatment in patients with newly diagnosed COPD. ${ }^{3}$ In the 2019 GOLD update, ICS are now recommended as the first choice only for some patients belonging to GOLD group D, and only in combination with LABAs (Figure 1). ${ }^{3}$ Long-term monotherapy with ICS is not presently recommended, but can be considered when associated with LABAs in those with a history of exacerbations and elevated eosinophils in spite of adequate therapy with long-acting bronchodilators. ${ }^{3}$ However, it is worthwhile noting that long-term use of ICS in either dual or triple therapy has been associated with some complications and adverse effects, ${ }^{12-14}$ even if they are widely used in routine management of patients for many years. As also stated in the GOLD guidelines, ICS may increase the risk of side effects including pneumonia. ${ }^{3}$ Thus, there remains ongoing concern over the long-term use of ICS, despite their recommend use when combined with long-acting bronchodilators in individuals who are at increased risk of exacerbation. Indeed, ICS are still routinely prescribed to the most patients with COPD at high risk of exacerbations and elevated eosinophils, even if GOLD criteria for their administration are not met. ${ }^{15,16}$

Unfortunately, at present, there are no international recommendations that provide specific guidance for deprescribing ICS, despite the evidence suggesting that they can be withdrawn in many patients. Herein, the available evidence on the use of ICS is reviewed before proposing a simple management scheme to guide the most appropriate therapy for management of COPD and use of ICS.
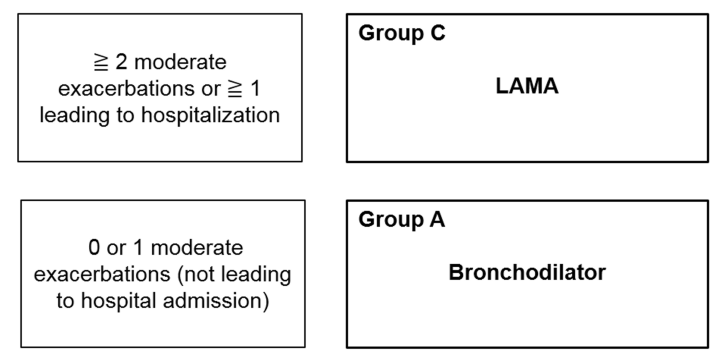

mMRC $0-1$ CAT $<10$
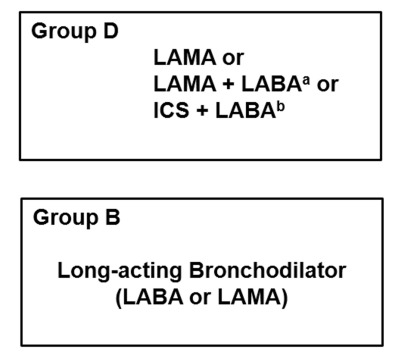

$\mathrm{mMRC} \geq 2 \mathrm{CAT} \geq 10$

Figure I GOLD 2019 algorithms for initial pharmacological treatment of COPD. ${ }^{\text {a} C o n s i d e r ~ i f ~ h i g h l y ~ s y m p t o m a t i c ~(e . g . ~ C A T>20) . ~}{ }^{b}$ Consider if eosinophils $>300$ cells/ $\mu$ L. Note: Reprinted with permission from: Global Initiative for Chronic Obstructive Lung Disease (GOLD) 2019 Report. Available from: https://goldcopd.org/gold-reports/. Accessed September 10, 2019. ${ }^{3} @ 2019$ Global Initiative for Chronic Obstructive Lung Disease. Available from: www.goldcopd.org. 


\section{Patient Phenotypes And ICS Withdrawal}

Given the wide range of COPD patient phenotypes and clinical presentations, with potentially diverse pathophysiological mechanisms, it is not likely that all patient subtypes will benefit from ICS, which may in part explain some of the discrepant results in the literature. There is, in fact, increasing evidence that patients with some phenotypes may benefit more than others from the addition of ICS to treatment regimens. In particular, it appears likely that those with asthma-COPD overlap (ACO), frequent exacerbators, and those with eosinophilic inflammation may benefit most from ICS.

\section{Asthma-COPD Overlap}

Although its prevalence is difficult to estimate, roughly one-fourth of patients with COPD may be considered to have ACO in which some feature of asthma and COPD coexist without presenting as a distinct syndrome. ${ }^{17}$ In a large analysis of over 5500 patients, among older individuals with COPD and asthma newly prescribed combination therapy with LABA and ICS led to a lower risk of death or COPD hospitalization vs newly prescribed LABAs alone. ${ }^{18}$ Real-world practice seems to confirm this, as only $18 \%$ of patients with ACO are not routinely given an ICS. ${ }^{19}$ Lee et al, have also provided clinical evidence that patients with ACO and mild-to-moderate limitations in airflow will show better lung function following treatment with an ICS/LABA combination after 3 months. ${ }^{20}$ Of note, in a database study of over 250,000 patients with ACO in Taiwan, use of LAMA or an ICS/ LABA combination was found to be associated with a lessened risk for acute exacerbations. ${ }^{21}$ Expert opinion seems to suggest that for patients without ACO, LAMA/ LABA may be appropriate for initiating therapy, while those who still have exacerbations may require additional treatments, possibly with ICS or PDE-4 inhibitors, taking into consideration the risk-benefit ratio in individual patients. ${ }^{22}$

\section{Frequent Exacerbators And Eosinophilic Inflammation}

Frequent exacerbators are another well-represented subclass of patients with COPD. The risk of exacerbation is normally defined according to the patient's history of exacerbations or the GOLD classification of airway limitation (i.e., high risk is $\geq 2$ exacerbations or $\geq 1$ hospitalization per year). Even considering this definition, many patients with moderate-to-severe COPD, or those classified as GOLD stage $\mathrm{C}$ and $\mathrm{D}$, are not frequent exacerbators, and thus do not meet qualifications for ICS therapy. ${ }^{17}$

The results from several studies have implicated that in both chronic bronchitis and COPD there is a relation between airway eosinophilia and exacerbations. ${ }^{23-26}$ In addition, an association between eosinophilia in sputum and response to steroids in COPD has been noted. ${ }^{27,28}$ In those with acute exacerbations of COPD, the administration of systemic corticosteroids has greater benefit in the presence of a blood eosinophil level of $\geq 2 \%$ vs a level $<2 \%){ }^{29,30}$ In this regard, two posthoc analyses of moderate-to-very severe COPD reported fewer moderate and severe exacerbations with eosinophil levels $\geq 2 \%$ than in those with $<2 \%$ if undergoing treatment with fluticasone furoate/vilanterol vs vilanterol as monotherapy. ${ }^{31,32}$ Analysis of the data in these trials has strongly suggested that blood eosinophil levels at baseline may, therefore, represent a valid means to monitor the reduction of exacerbations with ICS/LABA in those with COPD and a clinical history of moderate to severe exacerbations, as confirmed in a recent review. ${ }^{33}$

Based on the available clinical evidence, high blood levels of eosinophils can help predict future exacerbations, and may also be related to a more favorable response to ICS when added to LABA/LAMA, particularly so in those with a clinical history of frequent exacerbations, even if additional studies are still needed. ${ }^{34,35}$

\section{ICS Withdrawal: Clinical Evidence}

As noted in the review by Kaplan, despite the introduction of ICS into clinical practice over 2 decades ago, the option to continue or withdraw ICS in patients with COPD remains somewhat unsubstantiated, with conflicting evidence. ${ }^{36}$ The "step down" approach does not historically apply to COPD, but the disproportionate and incongruous use of ICS in COPD, along with the increased risk of associated adverse events including pneumonia, strongly suggests that ICS should be discontinued when the clinician deems that the risks outweigh the possible benefits. In fact, the advantage of ICS/LABA in combination compared to LABA alone in prevention of exacerbations was strongly disputed in a Cochrane meta-analysis several years ago. ${ }^{37}$ In 2017 , Calzetta carried out a meta-analysis of withdrawal of inhaled corticosteroids in COPD wherein it was reported that withdrawal of ICS did not significantly increase the rate 
of exacerbations, even if a clinically relevant risk of severe exacerbation was still present $(\mathrm{RR}>1.2) .{ }^{38}$ Moreover, withdrawal of ICS led to significant impairment of both lung function and quality of life, with a significantly shorter time to first exacerbation in those who withdrew from ICS.

At least three studies have examined the consequences of ICS withdrawal in real-life settings. In the first, OPTIMO, there was no significant increase in the risk of exacerbations during a 6-month period following discontinuation of ICS vs continued therapy with ICS/bronchodilator, and no evidence of deterioration in symptoms of COPD or lung function. ${ }^{39}$ In agreement with this possibility, the prospective, non-interventional 2-year DACCORD study from Germany studied the consequences of ICS withdrawal in 236 of 1022 patients with COPD. ${ }^{40}$ Patients in whom ICS was withdrawn had shorter duration of disease and better pulmonary function; among those in whom ICS was withdrawn, $74.2 \%$ did not experience exacerbations, which compares well with $70.7 \%$ among those continuing ICS; over the first year, exacerbation rates were 0.414 in those who withdraw and 0.433 in those who continued to receive ICS.

Chapman et al, reported the results of a 6-month trial investigating withdrawal of ICS in 1053 patients with COPD and no history of frequent exacerbations or asthma, but who were still being given triple therapy for $\geq 6$ months. ${ }^{41}$ After a 4-week run-in on tiotropium, salmeterol, and fluticasone propionate, patients were randomized to either abrupt discontinuation of ICS and switch to a single inhaler (IND/GLY) or to continue the same regimen. Withdrawal of ICS led to a small non-significant decline in $\mathrm{FEV}_{1}$ of $26 \mathrm{~mL}$ that occurred mostly with the first 4 weeks, and there was no increase in the rates of exacerbation.

The WISDOM trial studied the effects of ICS withdrawal on blood eosinophil count and exacerbations. ${ }^{42}$ Among the 2296 patients who received treatment following ICS withdrawal, the rate of moderate or severe exacerbations was similar in the overall population, but greater among those discontinuing ICS vs those continuing ICS in patients who had eosinophil counts $\geq 2 \%$ (RR 1.22; [95\% CI 1.02-1.48]), $\geq 4 \%$ (RR 1.63; [1.19-2.24]) or $\geq 5 \%$ (RR $1.82 ;[1.20-2.76])$. Thus, the increase seen in the rate of exacerbations further augmented as the eosinophil cut-off value increased. Interestingly, another analysis of the same populations showed that only patients with $>2$ exacerbations in the previous year and eosinophils $>300$ cells $/ \mu \mathrm{L}$ showed a significantly increased risk of exacerbations after withdrawal of ICS.

The AFFIRM COPD (Aclidinium and Formoterol Findings in Respiratory Medicine COPD) trial randomized 933 patients with moderate-to-severe COPD to aclidinium/ formoterol or salmeterol/fluticasone, both twice daily, over a 24-week period. ${ }^{43}$ Aclidinium/formoterol was superior to salmeterol/fluticasone when considering FEV1, showing a mean increase of $93 \mathrm{~mL}$ with LAMA/LABA over salmeterol/fluticasone. However, no difference between groups was seen when considering exacerbations, dyspnea, or quality of life. $^{43}$

The recent FLAME trial directly compared LABA/ LAMA to the ICS/LABA combination. ${ }^{44}$ In this large 52-week study, 3360 patients with moderate-to-severe COPD were randomized to twice-daily salmeterol and fluticasone or once-daily IND/GLY. At 1 year, patients who received IND/GLY experienced an 11\% lower risk of exacerbations vs those on salmeterol-fluticasone. Moreover, IND/GLY therapy was associated with a longer time to first exacerbation compared to those on salmeterolfluticasone [71 vs 51 days, 16\% lower risk $(\mathrm{p}<0.001)]$, fewer moderate and severe exacerbations, and lengthier time to first moderate or severe exacerbation. Moreover, compared to salmeterol-fluticasone, the effect of IND/GLY on exacerbations was not dependent on eosinophil count at baseline.

In a post hoc analysis of FLAME, IND/GLY provided greater or similar prevention of exacerbation than salmeterol-fluticasone in all groups when stratified by eosinophil levels and exacerbation history, thus supporting the use of the former to prevent exacerbations in moderate-to-very severe COPD. ${ }^{45}$ Lastly, a subgroup analysis of the FLAME study validated the consistent beneficial effects of IND/GLY compared to salmeterol-fluticasone on moderate/severe exacerbations that was not related to the history of exacerbations or treatment. ${ }^{46}$

\section{Beyond FLAME}

While the landmark trial FLAME trial showed greater reduction in exacerbations with LABA/LAMA than LABA/ICS in symptomatic patients with clinical history of exacerbations, an analysis of this trial has suggested that prevention of exacerbations with IND/GLY was similar or possibly superior to that with salmeterol-fluticasone at all ranges of eosinophil levels. ${ }^{47}$ This is in contrast to a post hocanalysis of WISDOM, which insinuated that at least some patients, namely those with history of exacerbations 
and high eosinophils levels, are at increased risk of exacerbations after ICS has been withdrawn. ${ }^{48}$ Another more recent post hoc analysis of FLAME investigated the effects of treatment on moderate to severe exacerbations considering both absolute (cut-offs of 150 and 300 cells $/ \mu \mathrm{L}$ ) and percentage $(2 \%, 3 \%$, and $4 \%)$ blood eosinophil count, in addition to exacerbation history ( 1 exacerbation and $\geq 2$ exacerbations). ${ }^{49}$ At levels $<150$ cells $/ \mu \mathrm{L}, \quad$ IND/GLY decreased the rate of moderate to severe exacerbations compared to salmeterol-fluticasone in those with 1 and $\geq 2$ exacerbations, while both treatments were similar in those with $\geq 150$ cells $/ \mu \mathrm{L}$ and $\geq 300$ cells $/ \mu \mathrm{L}$, independent of the history of exacerbation. IND/GLY was consistently more effective in the presence of low blood eosinophils, but has comparable efficacy in groups with higher eosinophils. This adds additional weight to the possibility that blood eosinophils can help to recognize patients who will likely benefit from ICS and LABA/LAMA. The results of this post hoc analysis further support the effectiveness of IND/GLY for preventing exacerbations in patients with moderate-tosevere COPD, and especially in those who are at greatest risk for exacerbations, further confirming the validity of the current GOLD guidelines that recommend LABA/LAMA over LABA/ICS in patients with COPD and at risk of exacerbations. ${ }^{17}$

\section{Guidelines On ICS Use In COPD}

Unfortunately, at present, there are no international guidelines that recommend how to perform withdrawal of ICS or provide a protocol for withdrawal when deemed necessary by the clinician; as the available data are not conclusive, more studies are needed to further understand in which patients withdrawal of ICS can be considered to be safe and beneficial.

In 2015, a consensus document from Spain was published, agreeing that therapy with ICS should be added to long-acting bronchodilators in the presence of frequent exacerbations as well as in patients with ACOS; ICS should not, however, be added to LABA to ameliorate pulmonary function. ${ }^{50}$ Moreover, these experts further reached the consensus that withdrawal of ICS in patients with stable disease is possible, even if no consensus reached on how to achieve this. Recommendations were mostly limited to stating that withdrawal of ICS in COPD is possible, that patients discontinuing ICS should be monitored, and that tapering should be used to withdraw ICS. Following changes to the GOLD document in 2017, in which impaired lung function is no longer considered as a determinant for risk of exacerbation, many COPD patients can now be considered to belong to group $\mathrm{B}$, with a low risk of exacerbations and clinically significant symptoms, ${ }^{17}$ and some considerations have been made in this regard. ${ }^{51}$

Previous authors have attempted to provide algorithms for withdrawing ICS in patients with COPD. ${ }^{36}$ The algorithm proposed by Kaplan takes into consideration exacerbation risk, according to GOLD, but also the emergent ACOS subgroup, as stated in the GINA/GOLD Consensus Statement. The algorithm further considers potential markers of eosinophilia, with a stepwise withdrawal protocol using dual bronchodilators that is mainly based on data from the WISDOM trial. Briefly, the algorithm consists of 5 steps in which current management is reviewed and the risk-benefits of continuing ICS therapy are assessed, considering ACO, frequency of exacerbations, and other potential markers such as eosinophils (sputum $\geq 3 \%$, blood eosinophils $\geq 300$ cells $/ \mu \mathrm{L}$ ). A decision is then made to withdraw (or not) ICS therapy. If withdrawn, a stepwise approach is taken, with possible step-up and step-down of ICS doses. Bronchodilation therapy with LABA/LAMA is optimized, and patients are followed regularly every 3 months. While oversimplified in the present discussion, other authors have held that such a proposal is somewhat complex and difficult to adopt in daily clinical practice. ${ }^{52}$

As such, other algorithms have been recently developed. The first is a simple treatment algorithm for inhaled pharmacotherapy based on dyspnea. ${ }^{53}$ Patients are subgrouped based on the presence of low $(<2 \mathrm{mMRC}$ dyspnea scale) or high ( $\geq 2 \mathrm{mMRC}$ dyspnea scale) dyspnea. If the patient has a low score, one long-acting bronchodilator is given, while two bronchodilators are given if the patient has a high score. In the presence of $\geq 2$ exacerbations in the prior year (keeping in mind that even a patient with one severe exacerbation and hospitalization is considered a frequent exacerbator), ICS are added to treatment, independently of the degree of dyspnea. The algorithm was also validated on 100 patients who were receiving care in primary and tertiary settings.

In a second simplified algorithm proposal, the choice of withdrawing or continuing ICS is initially based on stratification for the presence of ACO. ${ }^{52}$ In patients with FEV1 $>50 \%$ and without previous exacerbations, ICS should be discontinued. In those with ACO and who had exacerbations in the prior year, the benefits exceed the risks associated with withdrawal of ICS. Patients with FEV1 $>50 \%$ and exacerbations in the prior year as well 
as those with FEV1 $<50 \%$ without exacerbations should be carefully evaluated for withdrawal of ICS. As such, therapy with a dual bronchodilator should be continued to ensure that there is no increase in the risk of exacerbations. In patients with FEV1 $<50 \%$ and exacerbations in the prior year, as well as in those with ACO and no exacerbations, discontinuation of ICS should only be considered in those who have a substantial risk of serious side effects related to use of ICS. Close follow-up is essential.

\section{Shortcomings In Daily Practice}

In line with current clinical practice guidelines for COPD, the addition of ICS to long-acting $\beta 2$ agonist therapy is advocated only in those with moderate-to-severe disease who are at increased risk of exacerbations, even if fixeddose combinations of ICS/LABA are often used in contradiction of current recommendations in patients who are at a low risk of exacerbations. The available evidence from controlled trials adds weight to the supposition that ICS can be reasonably discontinued, from both safety and efficacy standpoints, in patients with stable COPD and in those for whom ICS therapy is not indicated; in the majority of patients, discontinuation is not likely to have unfavorable effects on pulmonary function, overall health status, or lead to a greater risk of exacerbations. Due to the lack of international guidelines, several groups have proposed algorithms for withdrawing ICS in patients with COPD. While the complexity of these algorithms may differ, all adhere to the principles of the most recent GOLD guidelines, even if their solid validation remains a weak point for their implementation. Nonetheless, all are also based on the underlying principle that ICS therapy is related to an increased risk of potentially serious adverse effects and complications, and as such, its use should be restricted to a minority of patients after careful evaluation of the individual risk-benefit profile.

\section{Deprescribing ICS In Routine Practice}

Following withdrawal of ICS, dual bronchodilator therapy should continue and patients should be carefully watched. Moreover, ICS therapy may be discontinued either abruptly or via gradual dose reduction in a stepwise fashion, but in any case, close monitoring is essential. Patients should not experience a decline in lung function during withdrawal. Particular care is warranted in high-risk patients who have frequent exacerbations or in patients with poor pulmonary function and being given a high dose of ICS. This is especially true when considering initiating a patient on ICS therapy or the discontinuation of ICS in patients who are already on long-term therapy. While promising, the role of elevated blood eosinophils as a marker to identify patients for treatment with ICS is still being debated, and further clinical studies are needed. Indeed, the available data support a role for ICS in the presence of eosinophil levels $\geq 300$ cells $/ \mu \mathrm{L}$. In the absence of unequivocal guidance, clinicians should continue to carefully evaluate and treat patients on an individual basis.

\section{Current GOLD Recommendations}

The GOLD 2019 strategy proposed a strategy for initiating pharmacological treatment of COPD that utilizes individualized evaluation of symptoms and exacerbations; ICS are considered as the first choice only in some GOLD D patients with particular characteristics such as blood eosinophil $\geq 300$ cells $/ \mu \mathrm{L}$ (in treatment-naïve patients) or history of asthma (Figure 1). ${ }^{3}$ This recommendation anyway comes together with the alert of possible development of pneumonia, so that ICS should be used during initial therapy only after considering its potential benefits and risks. The current GOLD 2019 strategy recommends a 3-step review for assessment and adjustment for which escalation, or switching the inhaler device or agent used within the same class may be considered as appropriate. The patient's response to escalation of treatment should always be monitored, and deescalation should be taken into consideration when there is no clinical benefit and/or in the presence of side effects. Clinicians can also consider de-escalation in patients with COPD who are receiving treatment and who have some symptoms that may require less intensive treatment, but in any can should this should be undertaken under close medical supervision. ICS withdrawal is currently recommended in COPD patients who experience adverse effects from ICS treatment as well as patients with inappropriate ICS treatment or those not showing benefits from the same treatment. Unfortunately, GOLD recommendations do not provide any suggestion on how to do this withdrawal (abruptly or with ICS dose tapering, even if off-label) and what phenotype of patients should be considered for this therapeutic re-organization. In this regard, one might consider ICS withdrawal in those with low eosinophil counts, no ACO, or ICS-related adverse events.

Interestingly, the IPCRG group has recently issued an algorithm for ICS withdrawal by simply assessing if the patient has asthma features or high exacerbation risk, and gives 
recommendations on the possibility to continue ICS treatment or to re-organize COPD maintenance treatment in favor of a double bronchodilator treatment (with no ICS added). ${ }^{54}$

\section{Proposal Of A Simple Management Tool For COPD}

Within the context of the above, an easy tool that gives physicians a support to guide the most appropriate COPD management seems particularly useful (Figure 2). The question of if not needed "the ICS should be abruptly withdrawn or the dose should be reduced gradually until full withdrawal" has no strong evidence-based answer at this time. What is important is the acknowledgement of a need to re-evaluate treatment for all COPD patients and in light of the ancient principle "first do not harm" any

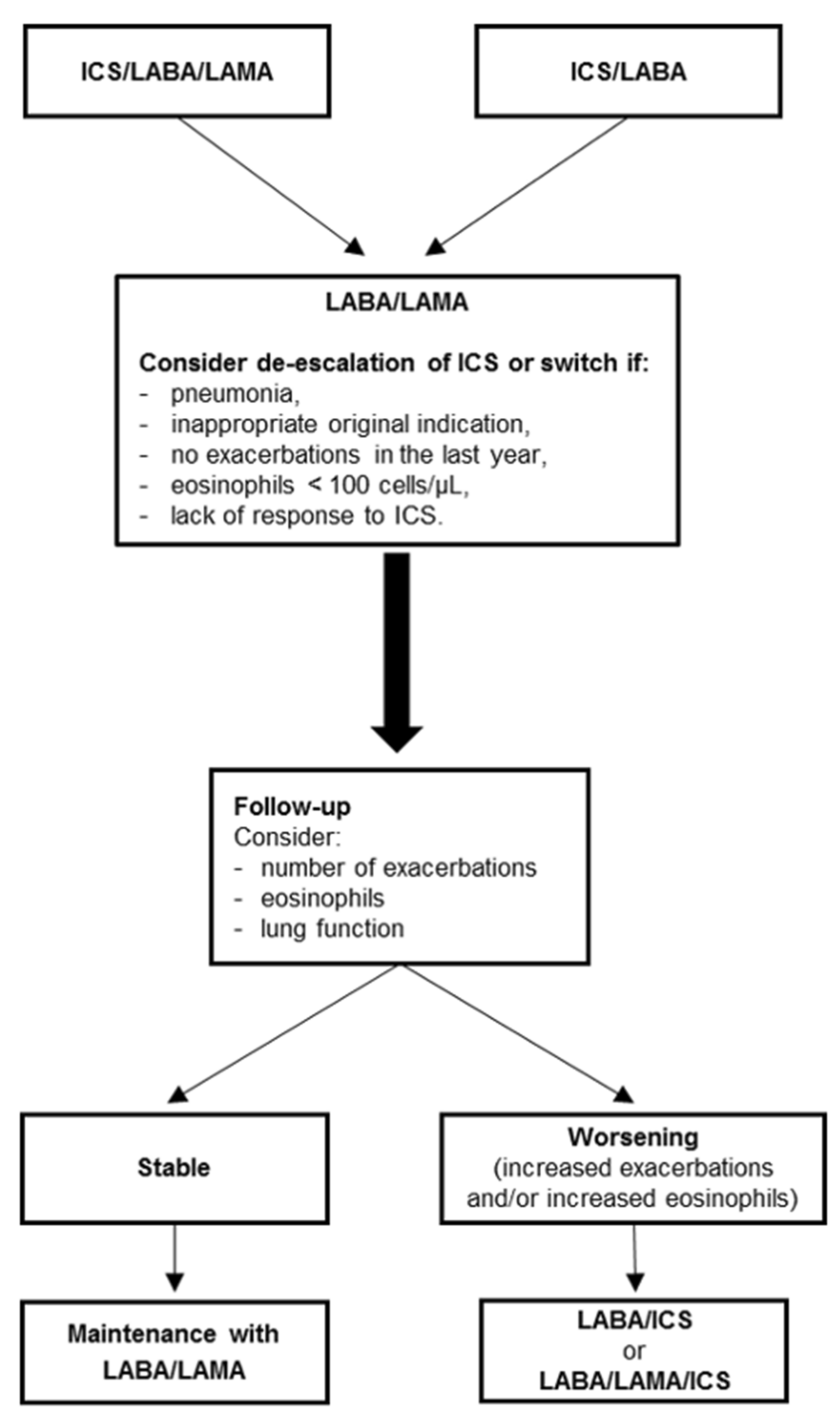

Figure 2 Decisional tool to guide the most appropriate management of COPD Stable disease is defined as no acute exacerbation of symptoms in the past year. unnecessary or potentially harmful treatment should be withdrawn, to put in practice the therapeutic re-organization that aims to a personalized medicine that is currently quite far from COPD management in routine clinical practice. Lastly, it should be noted that the proposed tool was not developed using formal methodology, but rather on clinical experience and review of the literature. It has also not escaped our attention that the simple tool proposed will require formal validation.

\section{Acknowledgments}

Editorial assistance for the manuscript was provided by Dr. Patrick Moore, on behalf of Health Publishing \& Services srl and supported by an unrestricted grant from Novartis Farma Italy. Dr. Moore declares there are no potential conflicts of interest relating to his editorial assistance.

\section{Disclosure}

Claudio Micheletto reports personal fees from AstraZeneca, GSK, Menarini, Guidotti, Berlin Chemie, Novartis, Zambom, and Boehringer Ingelheim, outside the submitted work. Marco Contoli reports grants and personal fees from AstraZeneca and Chiesi, and personal fees from ALKAbello, Novartis, Zambon, GlaxoSmithKline, and Boehringer Ingelheim, outside the submitted work. Fabiano Di Marco reports grants, personal fees, and non-financial support from AstraZeneca, Boehringer Ingelheim, Chiesi, Novartis, Menarini, Malesci, Guidotti, TEVA, and Zambon, outside the submitted work. Pierachille Santus reports grants and personal fees from Boehringer Ingelheim and AstraZeneca, grants from Chiesi Farmaceutici and Almirall, and personal fees from ALK-Abello, Berlin Chemie, GSK, Sanofi, and Zambon Italia, during the conduct of the study. The authors report no other conflicts of interest in this work.

\section{References}

1. Lopez AD, Shibuya K, Rao C, et al. Chronic obstructive pulmonary disease: current burden and future projections. Eur Respir J. 2006;27 (2):397-412. doi:10.1183/09031936.06.00025805

2. Mathers CD, Loncar D. Projections of global mortality and burden of disease from 2002 to 2030. PLoS Med. 2006;3(11):e442. doi:10.1371/ journal.pmed.0030442

3. Global initiative for chronic obstructive lung disease (GOLD) 2019 report. Available from: https://goldcopd.org/gold-reports/. Accessed September 10, 2019.

4. Kew KM, Dias S, Cates CJ. Long-acting inhaled therapy (beta-agonists, anticholinergics and steroids) for COPD: a network meta-analysis. Cochrane Database Syst Rev. 2014;3:CD010844.

5. Ohar JA, Donohue JF. Mono- and combination therapy of long-acting bronchodilators and inhaled corticosteroids in advanced COPD. Semin Respir Crit Care Med. 2010;31(3):321-333. doi:10.1055/s-0030-125 4072 
6. Vincken W, Aumann J, Chen H, Henley M, McBryan D, Goyal P. Efficacy and safety of coadministration of once-daily indacaterol and glycopyrronium versus indacaterol alone in COPD patients: the GLOW6 study. Int J Chron Obstruct Pulmon Dis. 2014;9:215-228. doi:10.2147/COPD.S51592

7. Cazzola M, Di Marco F, Santus P, et al. The pharmacodynamic effects of single inhaled doses of formoterol, tiotropium and their combination in patients with COPD. Pulm Pharmacol Ther. 2004;17 (1):35-39.

8. van Noord JA, Aumann JL, Janssens E, et al. Comparison of tiotropium once daily, formoterol twice daily and both combined once daily in patients with COPD. Eur Respir J. 2005;26(2):214-222. doi:10.1183/09031936.05.00140404

9. James GD, Donaldson GC, Wedzicha JA, Nazareth I. Trends in management and outcomes of COPD patients in primary care, 2000-2009: a retrospective cohort study. NPJ Prim Care Respir Med. 2014;24:14015. doi:10.1038/npjpcrm.2014.15

10. Di Marco F, Santus P, Terraneo S, et al. Characteristics of newly diagnosed COPD patients treated with triple inhaled therapy by general practitioners: a real world Italian study. NPJ Prim Care Respir Med. 2017;27(1):51. doi:10.1038/s41533-017-0051-9

11. Zheng Y, Zhu J, Liu Y, et al. Triple therapy in the management of chronic obstructive pulmonary disease: systematic review and metaanalysis. BMJ. 2018;363:k4388. doi:10.1136/bmj.k4029

12. Calverley PMA, Stockley RA, Seemungal TAR, et al. Reported pneumonia in patients with COPD: findings from the INSPIRE study. Chest. 2011;139(3):505-512. doi:10.1378/chest.09-2992

13. Papi A, Vestbo J, Fabbri L, et al. Extrafine inhaled triple therapy versus dual bronchodilator therapy in chronic obstructive pulmonary disease (TRIBUTE): a double-blind, parallel group, randomised controlled trial. Lancet. 2018;391(10125):1076-1084. doi:10.1016/ S0140-6736(18)30206-X

14. Price D, Yawn B, Brusselle G, Rossi A. Risk-to-benefit ratio of inhaled corticosteroids in patients with COPD. Prim Care Respir J. 2013;22(1):92-100. doi:10.4104/pcrj.2012.00092

15. Suissa S, Barnes PJ. Inhaled corticosteroids in COPD: the case against. Eur Respir J. 2009;34(1):13-16. doi:10.1183/09031936. 00190908

16. Vestbo J, Vogelmeier C, Small M, Higgins V. Understanding the GOLD 2011 strategy as applied to a real-world COPD population. Respir Med. 2014;108(5):729-736. doi:10.1016/j.rmed.2014.03.002

17. Vogelmeier CF, Criner GJ, Martinez FJ, et al. Global Strategy for the Diagnosis, Management, and Prevention of Chronic Obstructive Lung Disease 2017 Report. GOLD Executive Summary. Am J Respir Crit Care Med. 2017;195(5):557-582. doi:10.1164/ rccm.201701-0218PP

18. Gershon AS, Campitelli MA, Croxford R, et al. Combination longacting beta-agonists and inhaled corticosteroids compared with longacting beta-agonists alone in older adults with chronic obstructive pulmonary disease. JAMA. 2014;312(11):1114-1121. doi:10.1001/ jama.2014.11432

19. Ding B, Small M. Treatment trends in patients with asthma-COPD overlap syndrome in a COPD cohort: findings from a real-world survey. Int J Chron Obstruct Pulmon Dis. 2017;12:1753-1763.

20. Lee SY, Park HY, Kim EK, et al. Combination therapy of inhaled steroids and long-acting beta2-agonists in asthma-COPD overlap syndrome. Int J Chron Obstruct Pulmon Dis. 2016;11:2797-2803. doi:10.2147/COPD.S114964

21. Yi-Fong Su V, Yang KY, Yang YH, et al. Use of ICS/LABA combinations or LAMA is associated with a lower risk of acute exacerbation in patients with coexistent COPD and asthma. J Allergy Clin Immunol Pract. 2018;6:1927-1935.

22. D’Urzo A, Donohue JF, Kardos P, Miravitlles M, Price D. A re-evaluation of the role of inhaled corticosteroids in the management of patients with chronic obstructive pulmonary disease. Expert Opin Pharmacother. 2015;16(12):1845-1860. doi:10.1517/14656566.2015.1067682
23. Bafadhel M, McKenna S, Terry S, et al. Acute exacerbations of chronic obstructive pulmonary disease: identification of biologic clusters and their biomarkers. Am J Respir Crit Care Med. 2011;184(6):662-671. doi:10.1164/rccm.201104-0597OC

24. Hargreave FE, Dolovich J, Pizzichini E, Pizzichini M. Airway eosinophilia in chronic bronchitis during exacerbations. Am J Respir Crit Care Med. 1996;153(5):1726-1727. doi:10.1164/ajrccm.153.5.8630628

25. Saetta M, Di Stefano A, Maestrelli P, et al. Airway eosinophilia in chronic bronchitis during exacerbations. Am J Respir Crit Care Med. 1994;150(6 Pt 1):1646-1652. doi:10.1164/ajrccm.150.6.7952628

26. Siva R, Green RH, Brightling CE, et al. Eosinophilic airway inflammation and exacerbations of COPD: a randomised controlled trial. Eur Respir J. 2007;29(5):906-913. doi:10.1183/09031936.00146306

27. Brightling CE, Monteiro W, Ward R, et al. Sputum eosinophilia and short-term response to prednisolone in chronic obstructive pulmonary disease: a randomised controlled trial. Lancet. 2000;356(9240):14801485. doi:10.1016/S0140-6736(00)02872-5

28. Pizzichini E, Pizzichini MM, Gibson P, et al. Sputum eosinophilia predicts benefit from prednisone in smokers with chronic obstructive bronchitis. Am J Respir Crit Care Med. 1998;158(5 Pt 1):1511-1517. doi:10.1164/ajrccm.158.5.9804028

29. Bafadhel M, Davies L, Calverley PM, Aaron SD, Brightling CE, Pavord ID. Blood eosinophil guided prednisolone therapy for exacerbations of COPD: a further analysis. Eur Respir J. 2014;44(3):789791. doi:10.1183/09031936.00062614

30. Bafadhel M, McKenna S, Terry S, et al. Blood eosinophils to direct corticosteroid treatment of exacerbations of chronic obstructive pulmonary disease: a randomized placebo-controlled trial. Am J Respir Crit Care Med. 2012;186(1):48-55. doi:10.1164/rccm.201108-15 $53 \mathrm{OC}$

31. Dransfield MT, Bourbeau J, Jones PW, et al. Once-daily inhaled fluticasone furoate and vilanterol versus vilanterol only for prevention of exacerbations of COPD: two replicate double-blind, parallelgroup, randomised controlled trials. Lancet Respir Med. 2013;1 (3):210-223. doi:10.1016/S2213-2600(13)70040-7

32. Pascoe S, Locantore N, Dransfield MT, Barnes NC, Pavord ID. Blood eosinophil counts, exacerbations, and response to the addition of inhaled fluticasone furoate to vilanterol in patients with chronic obstructive pulmonary disease: a secondary analysis of data from two parallel randomised controlled trials. Lancet Respir Med. 2015;3(6):435-442. doi:10.1016/S2213-2600(15)00106-X

33. Pavord ID, Lettis S, Locantore N, et al. Blood eosinophils and inhaled corticosteroid/long-acting beta-2 agonist efficacy in COPD. Thorax. 2016;71(2):118-125. doi:10.1136/thoraxjnl-2015-207021

34. Barnes NC, Sharma R, Lettis S, Calverley PM. Blood eosinophils as a marker of response to inhaled corticosteroids in COPD. Eur Respir J. 2016;47(5):1374-1382. doi:10.1183/13993003.01370-2015

35. Kostikas K, Brindicci C, Patalano F. Blood eosinophils as biomarkers to drive treatment choices in asthma and COPD. Curr Drug Targets. 2018;19:1882-1896. doi:10.2174/1389450119666180212120012

36. Kaplan AG. Applying the wisdom of stepping down inhaled corticosteroids in patients with COPD: a proposed algorithm for clinical practice. Int J Chron Obstruct Pulmon Dis. 2015;10:2535-2548. doi:10.2147/COPD.S93321

37. Nannini LJ, Lasserson TJ, Poole P. Combined corticosteroid and long-acting beta(2)-agonist in one inhaler versus long-acting beta (2)-agonists for chronic obstructive pulmonary disease. Cochrane Database Syst Rev. 2012;9:CD006829.

38. Calzetta L, Matera MG, Braido F, et al. Withdrawal of inhaled corticosteroids in COPD: a meta-analysis. Pulm Pharmacol Ther. 2017;45:148-158. doi:10.1016/j.pupt.2017.06.002

39. Rossi A, Guerriero M, Corrado A; Group OAS. Withdrawal of inhaled corticosteroids can be safe in COPD patients at low risk of exacerbation: a real-life study on the appropriateness of treatment in moderate COPD patients (OPTIMO). Respir Res. 2014;15:77. doi:10.1186/1465-9921-15-77 
40. Vogelmeier C, Worth H, Buhl R, et al. "Real-life" inhaled corticosteroid withdrawal in COPD: a subgroup analysis of DACCORD. Int J Chron Obstruct Pulmon Dis. 2017;12:487-494. doi:10.2147/COPD. S125616

41. Chapman KR, Hurst JR, Frent SM, et al. Long-term triple therapy de-escalation to indacaterol/glycopyrronium in patients with chronic obstructive pulmonary disease (SUNSET): a randomized, double-blind, triple-dummy clinical trial. Am J Respir Crit Care Med. 2018;198(3):329-339. doi:10.1164/rccm.201803-040 $5 \mathrm{OC}$

42. Watz H, Tetzlaff K, Wouters EF, et al. Blood eosinophil count and exacerbations in severe chronic obstructive pulmonary disease after withdrawal of inhaled corticosteroids: a post-hoc analysis of the WISDOM trial. Lancet Respir Med. 2016;4(5):390-398. doi:10. 1016/S2213-2600(16)00100-4

43. Vogelmeier C, Paggiaro PL, Dorca J, et al. Efficacy and safety of aclidinium/formoterol versus salmeterol/fluticasone: a phase 3 COPD study. Eur Respir J. 2016;48(4):1030-1039. doi:10.1183/13993003. 00216-2016

44. Wedzicha JA, Banerji D, Chapman KR, et al. Indacaterol-glycopyrronium versus salmeterol-fluticasone for COPD. $N$ Engl J Med. 2016;374(23):2222-2234. doi:10.1056/NEJMoa1516385

45. Papi A, Kostikas K, Wedzicha JA, et al. Dual bronchodilation response by exacerbation history and eosinophilia in the FLAME study. Am J Respir Crit Care Med. 2018;197(9):1223-1226. doi:10. 1164/rccm.201709-1822LE

46. Vogelmeier CF, Chapman KR, Miravitlles M, et al. Exacerbation heterogeneity in COPD: subgroup analyses from the FLAME study. Int J Chron Obstruct Pulmon Dis. 2018;13:1125-1134. doi:10.2147/ COPD.S160011
47. Roche N, Chapman KR, Vogelmeier CF, et al. Blood eosinophils and response to maintenance chronic obstructive pulmonary disease treatment. Data from the FLAME trial. Am J Respir Crit Care Med. 2017;195(9):1189-1197. doi:10.1164/rccm.201701-0193OC

48. Calverley PMA, Tetzlaff K, Vogelmeier C, et al. Eosinophilia, frequent exacerbations, and steroid response in chronic obstructive pulmonary disease. Am J Respir Crit Care Med. 2017;196(9):12191221. doi:10.1164/rccm.201612-2525LE

49. Papi A, Kostikas K, Wedzicha JA, et al. Dual bronchodilation response by exacerbation history and eosinophilia in the FLAME study. Am J Respir Crit Care Med. 2017;197:1223-1226.

50. Alcazar Navarrete B, Casanova C, Miravitlles M, et al. "Correct use of inhaled corticosteroids in chronic obstructive pulmonary disease": a consensus document. Arch Bronconeumol. 2015;51(4):193-198. doi:10.1016/j.arbres.2014.11.001

51. Harlander M, Barrecheguren M, Turel M, Miravitlles M. Should patients switched from D to B in the GOLD 2017 classification be discontinued from inhaled corticosteroids? Copd. 2017;14(5):465468. doi:10.1080/15412555.2017.1342233

52. Miravitlles M, Cosio BG, Arnedillo A, et al. A proposal for the withdrawal of inhaled corticosteroids in the clinical practice of chronic obstructive pulmonary disease. Respir Res. 2017;18(1):198. doi:10.1186/s12931-017-0682-y

53. Cabrera C, Casanova C, Martin Y, et al. Agreement between a simple dyspnea-guided treatment algorithm for stable COPD and the GOLD guidelines: a pilot study. Int J Chron Obstruct Pulmon Dis. 2016;11:1217-1222. doi:10.2147/COPD.S100853

54. IPCRG. Evaluation of appropriateness of inhaled corticosteroid (ICS) therapy in COPD and guidance on ICS withdrawal. Available from: https://www.theipcrg.org/display/HOME/. Accessed September 11, 2019.

\section{Publish your work in this journal}

The International Journal of COPD is an international, peer-reviewed journal of therapeutics and pharmacology focusing on concise rapid reporting of clinical studies and reviews in COPD. Special focus is given to the pathophysiological processes underlying the disease, intervention programs, patient focused education, and self management protocols. This journal is indexed on PubMed Central, MedLine and CAS. The manuscript management system is completely online and includes a very quick and fair peer-review system, which is all easy to use. Visit http://www.dovepress.com/testimonials.php to read real quotes from published authors. 